\title{
Role of Drains in Intra-Abdominal Surgeries
}

\author{
Anurag Anupkumar Bhattacharjee ${ }^{1}$, Harshal Ramteke², Yashwant Lamture ${ }^{3}$ \\ 1, 2, 3 Department of General Surgery, Jawaharlal Nehru Medical College, \\ Datta Meghe University of Medical Sciences, Wardha, Maharashtra, India.
}

\section{ABSTRACT}

Drains have been used in surgery for many years to prevent the accumulation of bodily fluids and improving body function. Drain acts as an exit for passage of body fluids, blood \& pus that interfere with the process of wound healing or may act as a source for bacterial proliferation. Review of literature shows that assessment has been carried out regarding the impact of the drain on individual surgeries e.g., drain or no drain in colorectal surgeries. However, a collective assessment regarding abdominal surgeries as a whole has not been done.

A total of 14 studies conducted during the period 2000-2020 was included in this review. A collective review of these studies regarding the impact of the drain on various abdominal surgeries has been done, its findings \& limitations have been discussed, and its conclusion noted.

A comprehensive set of keywords or search terms were built like "prophylactic abdominal drainage", "wound infection," "to drain or not to", "intraperitoneal drainage", "post-operative length of hospital stay", "Surgical Site Infection (SSI)" or "risk factors". A systematic literature review search was performed in Medline, PubMed, Global health, Web of Science, Scopus, Cochrane, POPLINE, Open Grey Database, Adolec, Path, Gavi, WHO (World Health Organization) websites up to June 2020. The list of reference articles was retrieved and they were searched via automation \& manually.

Though drain usage has shown that it is nonessential or even detrimental in other surgeries such as colorectal resection, splenectomy, gastrojejunostomy, many operating surgeons fear that not putting routine intra-abdominal drain after a pancreaticoduodenectomy would not be beneficial. Prophylactic abdominal drainage in such surgeries does not show any benefit in with regard to reducing postoperative complications but also does not have any surgical benefit. Hence, there remains a controversy regarding the choices of drain usage which is left as an option to the surgeon's preference in his or her practice. Usage of drains in abdominal surgeries should be further analysed and reviewed.

\section{KEY WORDS}

Drains, Abdominal Surgeries, Drain Group, Non-Drain Group
Corresponding Author: Dr. Anurag Bhattacharjee. Department of General Surgery, Jawaharlal Nehru Medical College, Datta Meghe University of Medical Sciences, Wardha, Maharashtra, India. E-mail: siaa89@gmail.com

\section{DOI: $10.14260 / j e m d s / 2020 / 834$}

How to Cite This Article: Bhattacharjee AA, Ramteke H, Lamture Y. Role of drains in intra-abdominal surgeries. J Evolution Med Dent Sci 2020;9(50):38063810, DOI: 10.14260/jemds/2020/834

Submission 11-08-2020,

Peer Review 07-10-2020,

Acceptance 13-10-2020,

Published 14-12-2020.

Copyright (C) 2020 JEMDS. This is an open access article distributed under Creative Commons Attribution License [Attribution 4.0 International (CC BY 4.0)] 


\section{BACKGROUND}

The necessity of drain has always been a debatable topic in surgery. In certain sections of the surgical fraternity, ${ }^{1}$ it is believed that intra-abdominal operations should use drain; furthermore there are also those who continue to feel that drain is useless, and there are people as well who sit on the boundaries and use drain as a safety measure or perhaps as a precautionary measure due to his or her doubts. ${ }^{2}$ The opinions were largely based on individual choices and therefore the quantity \& type of drains available on the market show us that there is no perfect or suitable drain type that can be used generally in the wide field of abdominal surgery. ${ }^{3}$

In the field of surgery, the usage of drains has always been an important component, though the field has expanded into multiple super and sub-specialties, it continues to remain an important modality. ${ }^{1}$ Initial surgeons came out with different variants of it though rudimentary but it formed the base on which the current models are based. Many variants have been launched over the years, but their functions continue to remain the same that is to prevent the accumulation of bodily fluids and thereby improving the haemodynamic status of the patient. Surgical drains continue to play a vital role in the management of surgical patients. However, its usage continues to be a topic of contention. However, literature thus says, it is important that whenever it is indicated it should be practiced with proper wisdom \& care.

Several factors palliate against the usage of a multipurpose drain. The operating surgeon's dilemma is whether drain should be used or not. No one will question the need for drainage of unwanted collections, nobody can directly say yes or no to precautionary drain usage and hence, we are left with quote of Tait ${ }^{1}$ - Whenever there is doubt, the drain is to be put. This illogically logic statement that is still whispered today, but the query will be removed one day. Drainage occurs via gravitational pull and action of capillaries. A surgical knot is used to avoid movement or pulling out of drain from abdominal cavities. This process is seldom precautionary. ${ }^{4}$

Experts are using precautionary drainage on daily basis after abdominal procedures after its plus points were shown by Sims. But this theory was rejected by many in the surgical society. ${ }^{5}$ Doctors who prefer to use drains argue that drainage of the peritoneum can detect early problems at a fast rate thus providing an early option in helping improve lives while people who were not in favour say that drain of the peritoneum is not possible. Hence, it is of no use.

Hippocrates was the first one to ever document the use of surgical drains which he used for the treatment of empyema. It was rudimentary but the concept was simple, hollow tubes were used through which collected pus in the thorax detected via moving the chest and listening for the splashing sounds. The $^{3}$ side of the chest with the greatest quantity would be drained first followed by the latter. He rationalised this with a more medicinal approach and thereby began to make a prognosis.

The concept is that intra-abdominal drain application helps in early detection of various abdominal complications thereby preventing the early collection of pus-filled collections, reducing mortality and morbidity, and decreasing the overall postoperative stay. ${ }^{4}$ Regrettably, the concept of a precautionary drain is not on any database. So the importance of the overall use of the precautionary drain in abdominal surgeries remains a topic that shall be discussed in this paper.

Several trials were carried out to see the efficacy of precautionary drain applications after abdominal surgery. The conclusion shows that the use of precautionary application of drain peritoneal cavities is not useful in many scenarios. Despite all the data majority of the experts still employ precautionary drain application of the drain in deep cavities on regular basis thus adhering to the values of Tait. ${ }^{1}$ However, there is a sparsity of the data regarding the importance of the use of precautionary drainage. Thus the value of the precautionary drain remains disputable.

We wanted to evaluate the role of drains in intraabdominal surgeries.

\section{METHODS}

Search strategy: A comprehensive set of keywords or search terms were built like "prophylactic abdominal drainage", "wound infection," "to drain or not to", "intraperitoneal drainage", "post-operative length of hospital stay", "Surgical Site Infection (SSI)" or "risk factors". A systematic literature review search was performed in Medline, PubMed, Global health, Web of science, Scopus, Cochrane, POPLINE, Open Grey Database, Adolec, Path, Gavi, WHO websites were searched up to June 2020. The list of reference articles was retrieved and they were searched via automation \& manually.

\section{Data Extraction}

Data extraction was done by 2 authors into separate sheets using Excel 2020. Article selection and data extraction discrepancies were resolved through discussion. No specific date was predefined regarding publication. Automated \& manual deduplication was performed.

\begin{tabular}{|c|c|c|}
\hline Reference & Surgery Type / Name of Study & Comments \\
\hline $\begin{array}{l}\text { Imad Wajeh Al- } \\
\text { Shahwany et at } 2012^{6}\end{array}$ & $\begin{array}{l}\text { Drain or Not to Drain in Appendectomy } \\
\text { for Perforated Appendicitis }\end{array}$ & $\begin{array}{c}\text { Postoperative surgical site infection \& hospital stay was less in the non-drain group, hence its usage to be } \\
\text { reconsidered }^{6}\end{array}$ \\
\hline Cheng Y et al $2016^{7}$ & Prophylactic drainage in pancreatic surgery. ${ }^{7}$ & $\begin{array}{l}\text { Data was inconclusive whether pre-emptive use of abdominal drain has effects on the overall reduction of mortality } \\
\text { \& rate of postoperative complications. }{ }^{7}\end{array}$ \\
\hline $\begin{array}{l}\text { Shingo Tsujinaka et al } \\
\qquad 2011^{8}\end{array}$ & Drain vs No Drain After Colorectal Surgery ${ }^{8}$ & $\begin{array}{l}\text { Routine drainage did not } \\
\text { Have any advantage in colonic or rectal surgeries with resection } \\
\text { anastomosis, However, the available literature, the shows insufficient evidence to deny the usage of drain in rectal } \\
\text { cancer surgery performing TME }\end{array}$ \\
\hline $\begin{array}{l}\text { William E. Fisher et al } \\
\qquad 2011^{9}\end{array}$ & Intraperitoneal drainage in pancreatic resection ${ }^{9}$ & $\begin{array}{l}\text { Leaving the concept of pre-emptive drainage in pancreatic resection did } \\
\text { not increase the overall severity of severe post-operative complications. }{ }^{9}\end{array}$ \\
\hline $\begin{array}{l}\text { Dr. Prashant Raj } \\
\text { Pipariya }^{1} \text { et al } 2018\end{array}$ & $\begin{array}{l}\text { Comparative Study between Drain versus No Drain in } \\
\text { Elective Cholecystectomy }\end{array}$ & $\begin{array}{c}\text { Undergoing elective cholecystectomy where drain was kept can be avoided as it does not have any additional } \\
\text { benefit. }\end{array}$ \\
\hline $\begin{array}{l}\text { Chi-Leung Liu et al } \\
2004^{10}\end{array}$ & $\begin{array}{l}\text { Drainage After Hepatic resection is Contraindicated } \\
\text { With Chronic Liver Diseases }{ }^{10}\end{array}$ & $\begin{array}{l}\text { Routine drain usage after hepatic resection should be } \\
\text { avoided in patients with chronic liver diseases. }{ }^{10}\end{array}$ \\
\hline Wang Z et al $2011^{11}$ & $\begin{array}{c}\text { drainage versus no drain gastrectomy f surgeries for } \\
\text { stomach cancer }{ }^{11}\end{array}$ & There is insufficient data to support the usage of routine drain after gastrectomy for stomach cancer..$^{11}$ \\
\hline
\end{tabular}




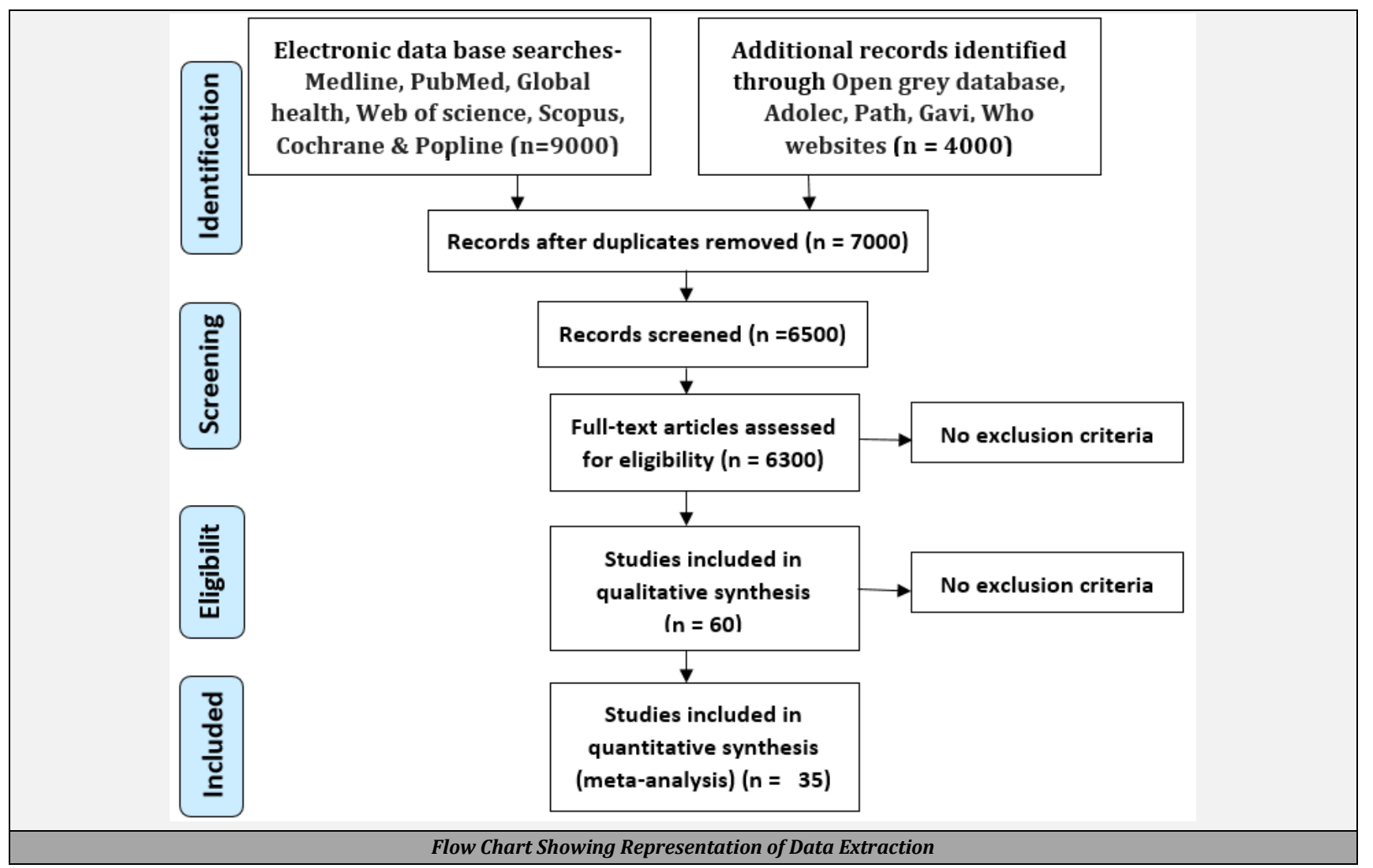

\section{DISCUSSION}

To understand the importance of drain in abdominal surgeries, a collective generalised analysis \& outcome discussion has been done regarding studies that have compared abdominal surgeries based on drain \& no drain group and their outcome. Surgeries and studies covered involved all the controversies associated with drains and the various post-operative events that occur with same were compared.

\section{Gastrointestinal Surgeries}

Petrowsky H (1966 to 2004) at el carried out a study which showed, evidence linked value of prophylactic drain usage in gastrointestinal surgery ${ }^{13}$ that was performed for comparing prophylactic drainage and non-drainage in GI (GastroIntestinal) surgery. Drain usage does not reduce the overall complication rate in surgeries done with primary anastomosis for large bowel or liver surgeries. However, drain usage was detrimental after liver resection in chronic liver disease and appendectomy. There was however, a requirement for preemptive drainage after oesophageal resection \& total gastrostomy due to the potential outcome of mortality in case of anastomotic \& gastric leakage. ${ }^{12}$

\section{Colorectal Surgeries}

\section{Cavaliere D et al}

Reviewed whether drainage is a must after anterior resection of the rectum. A search was conducted for comparing the use of drain \& non-drain in cases of colorectal anastomosis ${ }^{14}$ was done. A total of 1702 patients with rectal cancers who underwent anterior resection, while 1206 were with a pelvic drain and the rest 496 were without an abdominal drain.

Analysis showed that drain usage did not have any significant improvement in the outcomes of anastomotic leakage, but the overall re exploration rate during the last 30 days of postoperative recovery time \& mortality rates were statistically lower in the drained group ${ }^{13}$ Drainage after anterior resections did not provide any add on benefits linked with anastomotic leaks \& overall complication rates. However, an approximate $30 \%$ reduction in the mortality rate of the drained patients ${ }^{13}$ was seen.

\section{Rondelli $\boldsymbol{F}$}

Carried out a study regarding whether drainage is required in large bowel surgeries. ${ }^{15}$ The study included a total of 2277 patients where drainage was done to reduce overall leak rate $\&$ rate of re-exploration in patients who underwent anterior resection \& colorectal anastomosis as compared to patients without drain. The overall mortality \& infection rates were evaluated, but there wasn't a significant correlation found with the presence of drain. ${ }^{14}$ Drain placement helped in reducing the overall mortality rate in large bowel surgeries. ${ }^{14}$

\section{Pancreatic Surgery}

Conlon ${ }^{\mathrm{KC}}$ at el carried out a study to evaluate the importance of drainage after pancreatic resection in patients with peripancreatic tumors. Within the study among 179 included they were randomly divided into 90 who were women and 89 who were men. Pancreatic surgery was carried in 139 patients while distal pancreatectomy in the rest of the 40 cases. The postoperative complication occurred during the initial period in 107 patients (59\%) while there were no significant 
differences seen in the number or type of complications between groups. In the drained group 11 patients $(12.5 \%)$ developed pancreatic fistula. Patients with a drain were likely to develop a significant collection, intraabdominal abscess or fistula. 15 These results showed that drain should not be mandated or even standardised after pancreatic resection.

\section{Upper Gastrointestinal Surgeries}

Rajneesh Kumar at el studied the role of drain usage in cases of peptic ulcer perforations by comparing quantity of drains. ${ }^{16}$ The safety \& functioning of putting single drain near surgical site or in natural abdominal cavities \& no drain in cases of peritonitis due to peptic ulcer perforation was studied. It was carried on 60 patients ( 30 patients with no drain while the other 30 had drain). The perforations after thorough peritoneal lavage with warm saline and Metrogyl were closed with Grahm's patch. There wasn't any marked difference in the drain \& the non-drain group as other parameters were concerned. However, there was no marked difference seen on surgery duration, hospital stay, wound dehiscence and postoperative fever, intraperitoneal collection, or abscess formation. ${ }^{16}$ Drain usage was not beneficial in preventing infections, rather there were chances that it would cause drain block due to accumulation of debris, intestinal loops or omentum within the tubes which acted as a source of infection because of its foreign nature. There were chances that migration of bacteria into these peritoneal cavities can happen through these drains.

\section{Splenectomy}

R. Vecchio_studied surgical drains and their usage after open or laparoscopic splenectomy. ${ }^{17} 2009$ cases were taken for splenectomy which were performed either by open \& via laparoscopic approach, which included the "active" or "passive" drains were placed in $80 \%$ and $20 \%$ of cases, respectively. Drain usage did not change the overall risk of subsequent complications. It was independent from the drainage system that was used. Early removal of drain might have played a substantial role in the lowering the overall incidence of abdominal infections which were reported. Thus, usage of drains might play an important role in the early detection of postoperative bleeding.

\section{Controversies}

The modality of drain system usage in surgical field continues to be a topic of heated debate. There continues to be individuals who strongly believe that the drain usage has no added benefits and will continue to hinder the overall patient management. The opinions are based on a number of articles, research and personal experience, the fact that remains that the fluid, ${ }^{5}$ can or will become a potential source of contamination further causing delayed wound healing. However, there are many who believe that it protects or acts a early marker for detection of anastomotic leaks \& haemorrhage.

If we go back to look at our history the argument has been going on regarding the pros and cons of drains since a long time. One of the heavyweights in gastrointestinal surgery Theodor Billroth whose teachings are still followed today believed that drains had a key role in the future of surgery, but others continued to have a negative opinion of the same.
The other giants of his time Lawson Tait was a strong critic of his peers, but even he after long discussion's and arguments finally accepted the general notion of his time. His words are still used as a reason to put drain more out of a safety precaution rather than scientific data to back the same. The old saying which say, "When in doubt, drain" and "it is better to have and not need it than to need it and not have it" was followed for a long time. However, it cannot be given as an answer to the ever-increasing voices that are raised against its use as it is considered nowadays with recent advances a vague reply and furthermore an excuse to put drain.

Should drains be used and for how long a complicated question, but the diversity of answers suggests that no specific one is accurate. Every situation must be considered on its merit, and the most appropriate drainage method and material carefully selected. This policy is more practicable than a dogmatic approach. There many in the surgical profession who believe intraperitoneal drainage is a useless commodity and voiced their concern, there are also those who continue to sit on the side-lines and continue to use drain as a safety valve or perhaps as a precautionary measure due to their consciences.

\section{Summary}

Knowledge regarding the functional modality \& the currently available evidence for using the drains that may help in reducing unnecessary usage of drains. These drains are used for both prophylactic \& therapeutic purposes. The review of the studies conducted shows that the usage of drains in abdominal surgeries specifically clean-cut surgeries does not have any medical facts to support it.

A drain should always be brought out from a different incision than the main one as the drain will affect the main wound thus becoming a source of infection of the abdominal cavity. Furthermore, the stress on the site becomes a site for incisional hernia. ${ }^{13} \mathrm{~A}$ commonly accepted rule is that If a drain has less than $25 \mathrm{ml}$ in the last 24 hours (approximately $1 \mathrm{ml} /$ hr.) the drain can ideally be removed between 3 rd to 5 th day to prevent the development of the fistulous tract. However, there is no proven scientific data to prove the fact.

However, various studies show that there are many factors which support the facts that unnecessary insertions of the drain can lead to drain site infection, hospital psychosis, persistent drain site pain, unwillingness among patients for an oral diet with the drain in situ, lack of willingness / effort \& fear among patient / relatives to mobilise because of the drain in situ which furthermore prolongs the post-operative recovery period among patients with drains.

Within a surgeons mind, the purpose of putting a drain in scenarios such as colorectal anastomosis is to help exudate to flow out of the abdominal cavities rather than allowing it to accumulate, to avoid anastomotic dehiscence and infection. Haemorrhage, infection \& anastomotic leakage, are to be diagnosed early via prophylactic placement of drain.

Each drain is unique in its way and has a specific function to perform. Whilst removing a drain, the negative pressure is to be taken into consideration, if it is present it should be released first if not, it will lead to undue pain \& discomfort for the patients.

There continues to be sizeable chunk of the surgical community who reject routine use of prophylactic drain \& 
claim that they can cause infection that will lead to formation of serous fluid which will eventually lead to drain block \& obstruction.

\section{CONCLUSIONS}

Routine process of pre-emptive drainage in abdominal surgeries showed no benefit in reducing overall post-surgical complications or any surgical benefit for the same. However, available literature, does not have sufficient evidence to deny the use of drain, and assessment is required for the same. In spite of various articles and studies backing the theory that usage of drains should be on case basis or intra-operative basis.

Fear rather than scientific data appears to influence one's decision to put a drain. There are many in the surgical profession who believe intraperitoneal drainage is a useless commodity and voiced their concern, there are also those who continue to sit on the side-lines and continue to use drain as a safety valve or perhaps as a precautionary measure.

Financial or other competing interests: None.

Disclosure forms provided by the authors are available with the full text of this article at jemds.com.

\section{REFERENCES}

[1] Memon MA, Memon MI, Donohue JH. Abdominal drains: a brief historical review. Ir Med J 2001;94(6):164-6.

[2] Rather SA, Bari SU, Malik AA, et al. Drainage vs no drainage in secondary peritonitis with sepsis following complicated appendicitis in adults in the modern era of antibiotics. World J Gastrointest Surg 2013;5(11):300-5.

[3] Sagar PM, Couse N, Kerin M, et al. Randomized trial of drainage of colorectal anastomosis. $\mathrm{Br} \mathrm{J}$ Surg 1993;80(6):769-71.

[4] Durai R, Mownah A, Ng P. Use of drains in surgery: a review. J Perioper Pract 2009;19(6):180-6.
[5] HerniaSurge Group. International guidelines for groin hernia management. Hernia 2018;22(1):1-165.

[6] Al-Shahwany IW,Hindosh LN, Rassam RM, et al. Drain or not to drain in appendectomy for perforated appendicitis Iraqi postgraduate Medical Journal 2012;11:349-52.

[7] Cheng Y, Xia J, Lai M, et al. Prophylactic abdominal drainage for pancreatic surgery. Cochrane Database Syst Rev 2016;10(10):CD010583.

[8] Tsujinaka S, Konishi F. Drain vs No drain after colorectal surgery. Indian J Surg Oncol 2011;2(1):3-8.

[9] Fisher WE, Hodges SE, Silberfein EJ, et al. Pancreatic resection without routine intraperitoneal drainage. HPB (Oxford) 2011;13(7):503-10.

[10] Liu CL, Fan ST, Lo CM, et al. Abdominal drainage after hepatic resection is contraindicated in patients with chronic liver diseases. Ann Surg 2004;239(2):194-201.

[11] Wang Z, Chen J, Su K, et al. Abdominal drainage versus no drainage post-gastrectomy for gastric cancer. Cochrane database Syst Rev 2015;(5):CD008788.

[12] Petrowsky H, Demartines N, Rousson V, et al. Evidencebased value of prophylactic drainage in gastrointestinal surgery: a systematic review and meta-analyses. Ann Surg 2004;240(6):1074-84.

[13] Cavaliere D, Popivanov G, Cassini D, et al. Is a drain necessary after anterior resection of the rectum? A systematic review and meta-analysis. Int J Colorectal Dis 2019;34(6):973-81.

[14] Rondelli F, Bugiantella W, Vedovati MC, et al. To drain or not to drain extraperitoneal colorectal anastomosis? A systematic review and meta-analysis. Color Dis 2014;16(2):035-42.

[15] Conlon KC, Labow D, Leung D, et al. Prospective randomized clinical trial of the value of intraperitoneal drainage after pancreatic resection. Ann Surg 2001;234(4):484-93.

[16] Kumar R, Hastir A, Chopra L, et al. Role of drains in cases of peptic ulcer perforations: comparison between single drain versus no drain. Int Surg J 2020;7 (2):404-7.

[17] Vecchio R, Intagliata E, Marchese S, et al. Surgical drain after open or laparoscopic splenectomy: is it needed or contraindicated? G Chir 2015;36(3):101-5. 